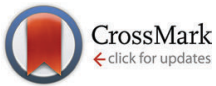

Cite this: Chem. Commun., 2015, 51, 9117

Received 6th January 2015

Accepted 24th April 2015

DOI: $10.1039 / c 5 c c 00101 c$

www.rsc.org/chemcomm

\section{A mussel-inspired adhesive with stronger bonding strength under underwater conditions than under dry conditions $\uparrow$}

\author{
Ailei Li, ${ }^{\text {ab }}$ Youbing $\mathrm{Mu}^{{ }^{* a}}$ Wei Jiang ${ }^{\mathrm{c}}$ and Xiaobo Wan ${ }^{{ }^{a}}$
}

A mussel-inspired adhesive based on a polyvinylpyrrolidone (PVP) backbone shows a much higher bonding strength under underwater/seawater conditions than under dry conditions. We reasoned that besides catechol moieties, the structure and properties of the backbone also play an important role in the realization of strong underwater bonding.

The strong underwater adhesion ability of mussels has attracted tremendous research interest to create biomimetic glues that can perform well under humid conditions or more extremely, underwater conditions. ${ }^{1}$ Although the real mechanism for mussel byssal adhesion is still not clear, it is generally accepted that one of the most important moieties in the glue protein secreted by mussels is the dihydroxyphenylalanine (DOPA) residue, which undergoes both covalent cross-linking and metal ion complexation and accounts for the strong underwater adhesion. ${ }^{2}$ Inspired by these facts, various polymers bearing catechol sidechains have been designed and synthesized to mimic the strong underwater adhesion properties of mussels. ${ }^{1 a-e, g, 3}$ Good to excellent bonding strength has been achieved when these biomimetic glues were obtained under dry conditions. However, the underwater bonding strength of these biomimetic adhesives is much weaker. For example, poly(3,4-dihydroxylstyrene-co-styrene) exhibits a recordhigh bonding strength up to 11.0 MPa on dry surfaces, ${ }^{3 a}$ while a terpolymer adhesive based on a similar backbone only exhibited

\footnotetext{
${ }^{a}$ Key Laboratory of Biobased Materials, Qingdao Institute of Bioenergy and Bioprocess Technology, Chinese Academy of Sciences, 189 Songling Road, Qingdao, Shandong Province 266101, P. R. China. E-mail: muyb@qibebt.ac.cn, wanxb@qibebt.ac.cn; Tel: +8653280662740

${ }^{b}$ University of Chinese Academy of Sciences, 19A Yuquan Road, Beijing 100049, P. R. China

${ }^{c}$ National Engineering Research Center for Organic Pollution Control and Resource Reuse, State Key Laboratory of Pollution and Resource Reuse, School of the Environment, Nanjing University, 22 Hankou Road, Nanjing, Jiangsu Province 210093, P. R. China

$\dagger$ Electronic supplementary information (ESI) available: Experimental details; eqn (S1); pictures of samples before and after the experiment; bonding strength on stainless steel; spectroscopic data. See DOI: $10.1039 / \mathrm{c} 5 \mathrm{cc} 00101 \mathrm{c}$
}

an underwater bonding strength around $0.3 \mathrm{MPa}^{1 e}$ The musselinspired adhesive based on a polyoxetane backbone reported previously by our group showed high bonding strength under dry conditions, ${ }^{4}$ however, it failed to bind under the same underwater conditions. Therefore, to realize strong underwater bonding is still challenging to date.

It seems that the catechol moiety is not the only factor that governs the underwater bonding performance. Here some questions rise: what kind of role does the protein backbone in the mussel byssal protein play in underwater bonding? What kind of inspiration could we get from the byssal protein backbone in the design of non-protein based mussel-inspired adhesives? Actually, even without catechol moieties, many proteins show some degree of glutinosity. For example, soybean protein has been used as a bio-mass based adhesive. ${ }^{5}$ We postulate that the amide bonds together with other functionalities in the proteins might provide an initial driving force for mussel byssal proteins to form strong interaction with the rocky surfaces. During our continuous efforts to prepare adhesives that mimic mussel proteins, ${ }^{1 h, 4}$ we realized that PVP might be a good candidate as the backbone for biomimetic glues, given that PVP itself is glutinous and shows certain similarity in structure to peptides (both containing amide bonds). Herein we would like to report a strong mussel-inspired adhesive that is based on a PVP backbone, the bonding strength of which under underwater conditions is higher than that under dry conditions, which was not reported before.

The synthesis of this biomimetic adhesive based on the PVP backbone is quite straightforward, as shown in Scheme 1. Poly( $N$-vinyl-2-prolidone-co-3-trimethylsiyl-propargyl- $N$-vinyl-2-prolidone) (copolymer 1, P(VP-co-TMSPG-VP)) was synthesized according to the

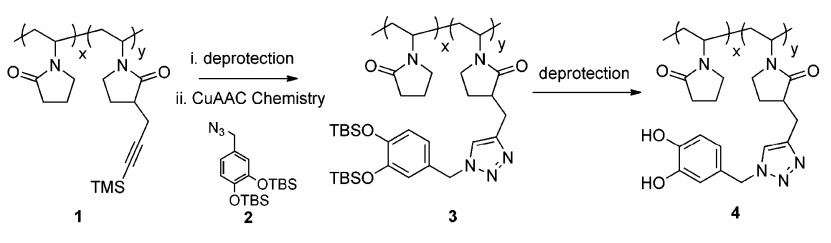

Scheme 1 Synthetic route toward PVP-based biomimetic adhesives. 
Table 1 Characterization data of copolymer $\mathbf{1}$ and $\mathbf{4}$

\begin{tabular}{|c|c|c|c|c|c|c|}
\hline \multicolumn{2}{|c|}{$\begin{array}{l}\text { TMSPG-VP } \\
\text { content }(\%)\end{array}$} & \multicolumn{3}{|c|}{ Copolymer 1} & \multicolumn{2}{|c|}{ Copolymer 4} \\
\hline $\begin{array}{l}\text { In } \\
\text { feed }\end{array}$ & $\begin{array}{l}\text { In } \\
\text { copolymer }\end{array}$ & $M_{\mathrm{n}}$ & PDI & $\begin{array}{l}\text { Yield } \\
(\%)\end{array}$ & $\begin{array}{l}M_{\mathrm{n}}{ }^{a} \\
\text { (cal.) }\end{array}$ & $\begin{array}{l}\text { Catechol } \\
\text { content }(\%)\end{array}$ \\
\hline 10 & 9.8 & 12216 & 1.47 & 92.2 & 13129 & 9.0 \\
\hline 20 & 18.4 & 3037 & 1.67 & 85.1 & 3432 & 14.5 \\
\hline 20 & 19.6 & 7229 & 1.72 & 91.0 & 8221 & 16.5 \\
\hline 20 & 18.9 & 9311 & 1.85 & 86.9 & 10551 & 16.0 \\
\hline 20 & 19.2 & 15169 & 2.65 & 88.7 & 17216 & 16.0 \\
\hline 30 & 28.0 & 12512 & 2.85 & 92.0 & 14806 & 23.5 \\
\hline
\end{tabular}

${ }^{a}$ The calculations were conducted according to eqn (S1) in the ESI.

reported procedure, and the molecular weight of the copolymer could be adjusted by controlling the initiator/monomer ratio. ${ }^{6}$ Copolymers synthesized at three different feeding ratios $(10,20$, $30 \mathrm{~mol} \%$ of TMSPG-VP) are listed in Table 1 . Since the average content of DOPA residues in mussel byssal proteins is around $20 \mathrm{~mol} \%{ }^{7}$ copolymers with different molecular weights ranging from $3 \mathrm{kDa}$ to $15 \mathrm{kDa}$ but with the fixed feeding ratio at $20 \mathrm{~mol} \%$ TMSPG-VP were synthesized to systematically investigate the influence of the molecular weight on the adhesive properties. Copolymer 1 was characterized using ${ }^{1} \mathrm{H}$ NMR and size-exclusive chromatography (ESI $\dagger$ ). The incorporation ratio of TMSPG-VP, which was determined by ${ }^{1} \mathrm{H}$ NMR analysis, was close to the feeding ratio, as indicated in Table 1. The trimethylsilyl group (TMS) was then removed and the resultant polymer was then grafted with tertbutyl-dimethyl-silanyl group (TBS) protected 4-(azidomethyl)benzene-1,2-diol 2 via $\mathrm{Cu}(\mathrm{I})$-catalyzed alkyne-azide cycloaddition click chemistry to give copolymer $3 .{ }^{4}$ The removal of the TBS protecting group from copolymer 3 afforded the final catecholgrafted copolymer 4 . Since both copolymers 3 and 4 are not soluble in THF, the molecular weight of copolymer 4 was calculated from that of copolymer $\mathbf{1}$ and is listed in Table 1, assuming that deprotection was completed and the grafting ratio determined from the ${ }^{1} \mathrm{H}$ NMR integration analysis would not lead to an obvious deviation of the calculated results from the real ones (see ESI $\dagger$ ). The obtained copolymer 4 was not soluble in water, but showed acceptable solubility in mixed $\mathrm{CH}_{2} \mathrm{Cl}_{2}$ and $\mathrm{MeOH}(\mathrm{V} / \mathrm{V}=1 / 1)$. It is worthwhile to point out that the solubility of copolymer 4 decreases with the increase of the catechol content. For example, if the initial feeding ratio of TMSPG-VP was $10 \mathrm{~mol} \%$, the obtained final copolymer showed the best solubility of $0.30 \mathrm{~g} \mathrm{~mL}$ in $\mathrm{CH}_{2} \mathrm{Cl}_{2} / \mathrm{MeOH}$. This number dropped to $0.02 \mathrm{~g} \mathrm{~mL}^{-1}$ when the feeding ratio increased to 30 mol\%. When the feeding ratio further increased to $40 \mathrm{~mol} \%$ (data not shown), the final copolymer became insoluble in most organic solvents. This is also a reason why we did not synthesize and test the adhesion performance of the copolymer with a catechol content more than $30 \mathrm{~mol} \%$.

With the copolymer $\mathbf{4}$ in hand, we tested their adhesion properties under both dry conditions and underwater conditions. Both tests were conducted at room temperature. The procedure for adhesion tests under dry conditions was similar to the reported one (see $\mathrm{ESI} \dagger$ ). ${ }^{1 b}$ For adhesion tests under underwater conditions, due to the low viscosity of the copolymer

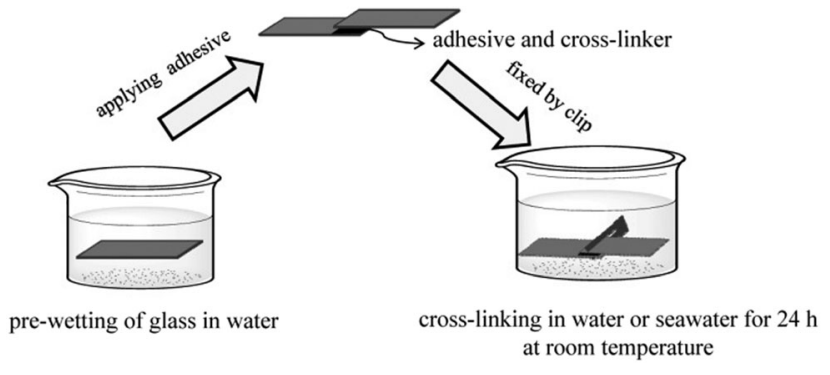

Fig. 1 Schematic illustration of underwater adhesion.

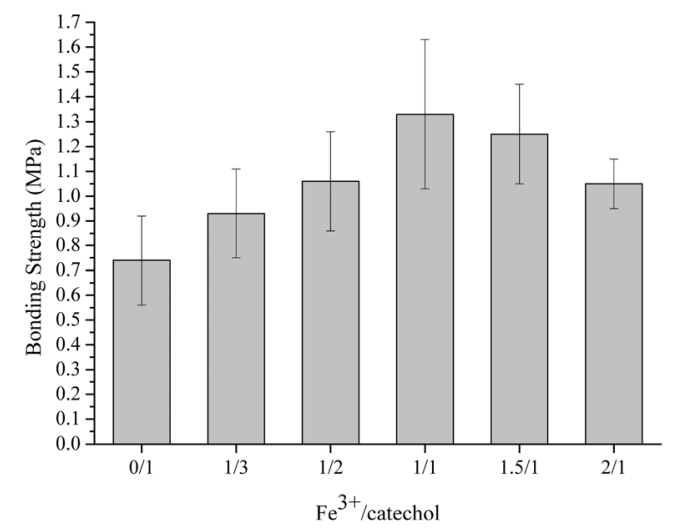

Fig. 2 Underwater bonding strength of copolymer 4 with 16.0 mol\% catechol grafted $\left(M_{n}=10551 \mathrm{Da}\right)$ as a function of the molar ratio of $\mathrm{FeCl}_{3}$ to catechol.

solution, the exact underwater condition was not applicable. Instead, the adherends were pre-wetted first, and the adhesive and $\mathrm{FeCl}_{3}$ solution were applied to the surface while it was still wet. The two adherends were then fixed using a clip, and immediately immersed into water or seawater and soaked for $24 \mathrm{~h}$ before test, as shown in Fig. 1. For constancy, the amount of the adhesive was fixed at $1.5 \mathrm{mg} \mathrm{cm}^{-2}$ in all cases. Glass was chosen as the major substrate for tests due to its relatively smooth surface.

In our preliminary studies, we found that copolymer 4 exhibited a high bonding strength under underwater conditions, as shown in Fig. 2. Even without $\mathrm{FeCl}_{3}$ as the cross-linker, copolymer 4 (16 mol\% catechol, $\left.M_{\mathrm{n}}=10551 \mathrm{Da}\right)$ showed an average bonding strength around $0.74 \mathrm{MPa}$. With the addition of $\mathrm{FeCl}_{3}$, the bonding strength increased and reached a maximum bonding strength at 1.63 MPa (average 1.33 MPa) when the molar ratio of $\mathrm{FeCl}_{3}$ to catechol reached 1:1. A further increase of the amount of the cross-linker caused a decrease of the bonding strength. So the optimal molar ratio of $\mathrm{FeCl}_{3}$ to catechol was set at 1:1 in all the other tests.

More surprisingly, we found that regardless of the molecular weight, the bonding strength of copolymer 4 under underwater conditions was higher than that under dry conditions, and further improved under under-seawater conditions. The bonding strength of copolymer 4 obtained from the initial feeding ratio of $20 \mathrm{~mol} \%$ TMSPG-VP with different molecular weights were compared, as shown in Fig. 3. In all cases, a substantial increase 


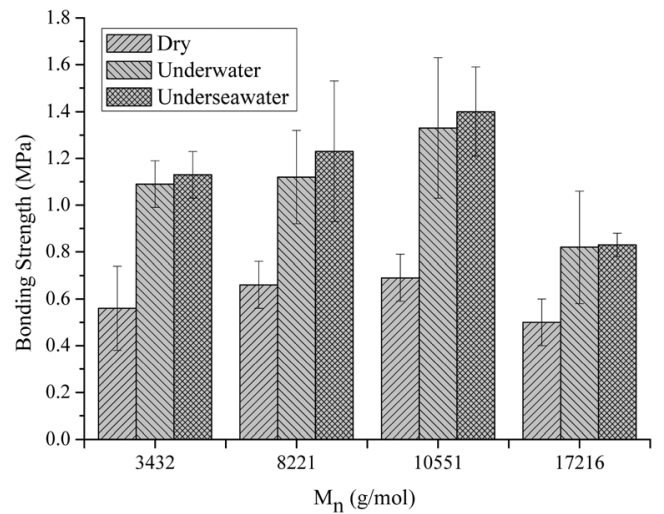

Fig. 3 Bonding strength of copolymer 4 with $\sim 16.0$ mol\% catechol grafted as a function of the molecular weight of copolymer 4 under different conditions.

was observed when the bonding experiments were carried out under underwater conditions. For example, copolymer 4 with molecular weight 3432 Da showed an average bonding strength of $0.56 \mathrm{MPa}$ under dry conditions, which increased to $1.09 \mathrm{MPa}$ under underwater conditions, and further increased to $1.13 \mathrm{MPa}$ under under-seawater conditions. Furthermore, the bonding strength increased with the increase of the molecular weight at the beginning and reached the maximum $(1.33 \mathrm{MPa})$ when $\mathrm{M}_{\mathrm{n}}$ is around $10 \mathrm{kDa}$. When $M_{\mathrm{n}}$ was further increased to $17 \mathrm{kDa}$, the bonding strength decreased to $0.82 \mathrm{MPa}$, and the enhancement caused by seawater almost diminished. The influence of the molecular weight of the adhesive on the adhesion performance is consistent with the bridging and nonbridging adhesive mode. ${ }^{2 h, i}$

The influence of the catechol content on the bonding strength was also investigated and the results are shown in Fig. 4 . Three copolymers with similar molecular weight (ranging from $10 \mathrm{kDa}$ to $15 \mathrm{kDa}$ ) but different catechol content $(9.0 \mathrm{~mol} \%, 16.0 \mathrm{~mol} \%$ and $23.5 \mathrm{~mol} \%$ ) were compared. All copolymers showed similar average bonding strength under dry conditions (ranging from $0.66 \mathrm{MPa}$ to $0.73 \mathrm{Ma}$ ), and all showed better underwater/seawater adhesion performance. For copolymers containing $9.0 \mathrm{~mol} \%$ catechol, the average underwater boding strength $(0.72 \mathrm{MPa})$

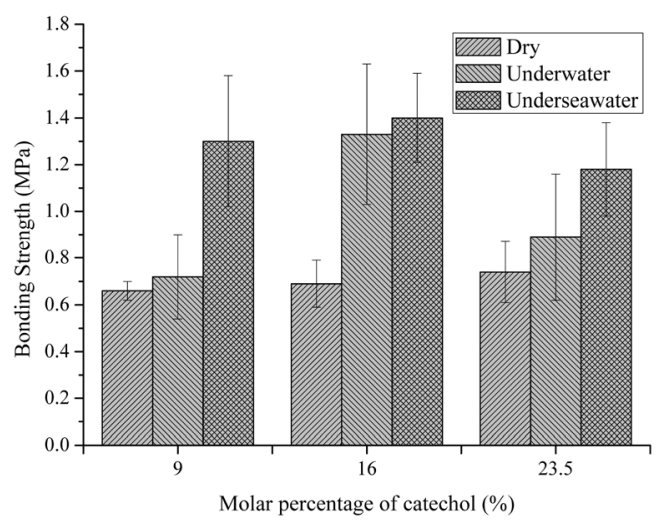

Fig. 4 Bonding strength of synthetic copolymer 4 as a function of catechol content grafted under different conditions. was slightly better than that under dry conditions ( $0.66 \mathrm{MPa})$, while the average under-seawater bonding strength was much higher $(1.30 \mathrm{MPa})$. When the catechol content increased to $16.0 \mathrm{~mol} \%$, a more obvious increase of the average underwater bonding strength (to $1.33 \mathrm{MPa}$ ) was observed, and the influence of seawater became smaller. With the further increase of the catechol content to $23.5 \mathrm{~mol} \%$, the average underwater bonding strength dropped to $0.89 \mathrm{MPa}$, and that under-seawater dropped to $1.18 \mathrm{MPa}$. Given that the loading amount of adhesive is low $\left(1.5 \mathrm{mg} \mathrm{cm}{ }^{-2}\right.$ ), such strong adhesion is amazing. For comparison, the best underwater adhesion on an aluminium substrate reported before $(0.4 \pm 0.2 \mathrm{MPa})$ of an adhesive based on polystyrene backbone was achieved at a loading amount of $4.32 \mathrm{mg} \mathrm{cm}^{-2} \cdot{ }^{1 e}$ Overall, the copolymer containing $16.0 \mathrm{~mol} \%$ catechol showed the best underwater bonding strength. This might result from the balance between the cohesion and adhesion, just as many other reported mussel-inspired adhesives. ${ }^{1 d, h, 4}$ Fig. S1 (in ESI $\dagger$ ) shows the samples before and after the experiment, as we can see from it, there is obvious discoloration of the adhesive before and after the test. As shown in the second picture in Fig. S1 (ESI $\dagger$ ), failure of adhesion mainly occurred in the two interfaces, namely failure of cohesion.

We also tested the performance of this PVP-based adhesive (16.5 mol\% catechol) on other substrates such as stainless steel. A similar trend was observed: under dry conditions, a rather low bonding strength (0.09 $\mathrm{MPa})$ was observed, which was improved to $0.26 \mathrm{MPa}$ under underwater conditions, and further improved to 0.40 MPa under under-seawater conditions (see Fig. S2, ESI $\dagger$ ).

The better underwater bonding strength over dry conditions was interesting, since in many other cases, mussel-inspired adhesives generally showed much stronger bonding strength under dry conditions compared with that under underwater conditions. ${ }^{1 b, e}$ It is worthwhile to point out that the design of mussel-inspired adhesives mainly focused on the attachment of catechols onto biocompatible polymer backbones, such as chitosan,,$^{1 f}$ poly(ethylene glycol) ${ }^{1 c, 8}$ poly(amino esters) etc. ${ }^{1 g}$ little attention was paid to the physical properties of the polymer backbone itself. Although theoretical calculation indicated that catechol molecules could bind directly to the surface and pushed water molecules aside to achieve the lowest energy configuration, this analysis is limited at the single catechol molecule level and could not be simply deduced to polymeric systems. ${ }^{2 e}$ If so, all polymers bearing catechol moieties should show good to excellent underwater bonding performance. Apparently, that is not the case. We considered that in polymers, things are more complicated and more factors such as the interaction of the polymer backbone with the wet surface should be taken into account. For example, if the polymer backbone is hydrophobic (such as polystyrene or polyoxetane), it tends to stay away from the hydrophilic surface, which will diminish the binding effect of catechol moieties.

We speculated that besides catechol moieties, the PVP backbone also played a very important role for strong underwater bonding in our case. As depicted in Fig. 5, the hydroxyl groups at the activated glass surface could act as the $\mathrm{H}$-bond donor (Fig. 5a), while the amide bonds in PVP act as the $\mathrm{H}$-bond 


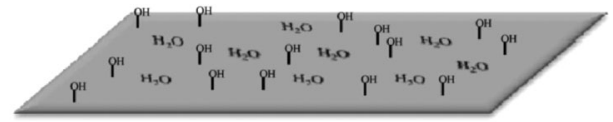

a

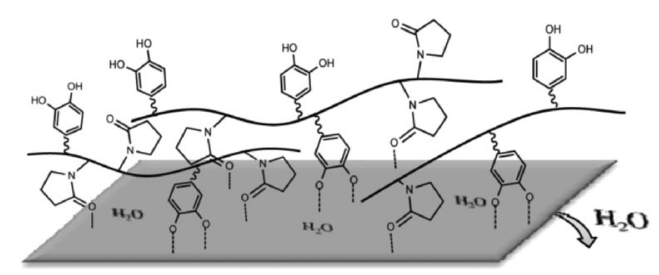

b

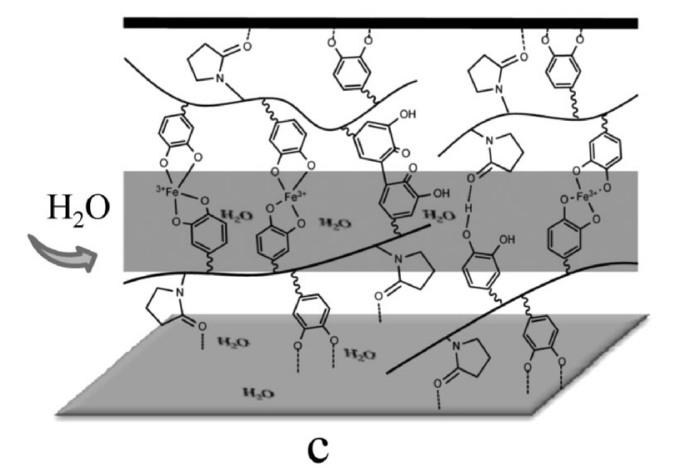

Fig. 5 Schematic illustration of the mechanism of adhesion and cohesion: (a) activated surface of glass; (b) initial adhesion of copolymer $\mathbf{4}$ to the wet surface of glass: the arrow shows that water molecules are repelled out from the surface; dashed lines represent $\mathrm{H}$-bonding formation; (c) the crosssectional image of two glasses bound together in water; the arrow shows that water molecules from the surroundings diffuse into the bulk adhesive.

acceptor, which could form strong H-bonding with the glass surface (Fig. 5b). Such interaction works together with the interaction between catechol moieties and the surface to repel water molecules out from the surface, and offers the initial adhesion of the polymer to the wet surface. Furthermore, once the two surfaces applied with copolymer $\mathbf{4}$ and $\mathrm{FeCl}_{3}$ were bound together and immersed into water, water molecules could slowly diffuse into the bulk copolymer due to the compatibility of water molecules with the PVP backbone, which facilitates the diffusion of $\mathrm{Fe}^{3+}$ ions inside the polymer to promote more homogenous cross-linking and complexation (Fig. 5c). This could be considered as a "water-promoted curing process". If it is under dry conditions, the diffusion rate of $\mathrm{Fe}^{3+}$ ions will be quite limited, which results in less effective crosslinking and complexation. This explains why the underwater bonding strength of copolymer 4 is stronger than that under dry conditions. Moreover, if this process occurs in seawater, the ions in seawater could also diffuse into the bulk copolymer and coordinate with catechol moieties which further enhance the bonding strength. It should be pointed out the balance between hydrophilicity of the polymer backbone and the insolubility of the polymer in water is also very important: unmodified PVP showed high bonding strength up to several MPa under dry conditions but lost its glutinosity when the same underwater test conditions were applied, since PVP is soluble in water.
PVP quaternized with catechol moieties ${ }^{9}$ also failed in underwater adhesive tests (performed in our laboratory) since it is soluble in water.

In summary, a mussel-inspired adhesive based on a PVP backbone was synthesized and its adhesive properties both under dry and underwater conditions were investigated. The most striking result is that this specific biomimetic adhesive shows a much higher bonding strength under underwater/ seawater conditions than under dry conditions. We believe there is still room to improve the underwater bonding performance, for example, the optimal catechol/ $/ \mathrm{FeCl}_{3}$ ratio might vary against molecular weight and catechol content and could be further adjusted, which will be subjected to investigation in the future. We reasoned that besides catechol moieties, the structure and properties of the backbone also played an important role in the realization of strong underwater bonding, which was overlooked in the design of other artificial mussel-inspired adhesives before. The introduction of a catechol moiety and the engineering of the polymer backbone should be both taken into consideration for the next generation of mussel-inspired adhesives that will show strong underwater bonding performance.

This work was supported by the " 100 Talents" Program from the Chinese Academy of Sciences and the Director Innovation Foundation for Young Scientists (Y472011106) from Qingdao Institute of Bioenergy and Bioprocess Technology.

\section{Notes and references}

1 (a) M. Yu and T. J. Deming, Macromolecules, 1998, 31, 4739; (b) J. Wang, C. Liu, X. Lu and M. Yin, Biomaterials, 2007, 28, 3456; (c) S. A. Burke, M. Ritter-Jones, B. P. Lee and P. B. Messersmith, Biomed. Mater., 2007, 2, 203; (d) C. R. Matos-Perez, J. D. White and J. J. Wilker, J. Am. Chem. Soc., 2012, 134, 9498; (e) J. D. White and J. J. Wilker, Macromolecules, 2011, 44, 5085; $(f)$ K. Yamada, T. Chen, G. Kumar, O. Vesnovsky, L. D. T. Topoleski and G. F. Payne, Biomacromolecules, 2000, 1, 252; $(g)$ H. Zhang, L. P. Bre, T. Zhao, Y. Zheng, B. Newland and W. Wang, Biomaterials, 2014, 35, 711; (h) A. Li, M. Jia, Y. Mu, W. Jiang and X. Wan, Macromol. Chem. Phys., 2015, 216, 450; (i) Y. Liu, K. Ai and L. Lu, Chem. Rev., 2014, 114, 5057.

2 (a) M. Yu, J. Hwang and T. J. Deming, J. Am. Chem. Soc., 1999, 121, 5825; (b) H. Lee, N. F. Scherer and P. B. Messersmith, Proc. Natl. Acad. Sci. U. S. A., 2006, 103, 12999; (c) Z. Xu, Sci. Rep., 2013, 3, 2914; (d) Y. Li, M. Qin, Y. Li, Y. Cao and W. Wang, Langmuir, 2014, 30, 4358; (e) S. A. Mian, L. M. Yang, L. C. Saha, E. Ganz, E. Ahmed and A. Muhammad, Langmuir, 2014, 30, 6906; $(f)$ J. Wang, M. N. Tahir, M. Kappl, W. Tremel, N. Metz, M. Barz, P. Theato and H.-J. Butt, Adv. Mater., 2008, 20, 3872; ( $g$ ) T. H. Anderson, J. Yu, A. Estrada, M. U. Hammer, J. H. Waite and J. N. Israelachvili, Adv. Funct. Mater., 2010, 20, 4196; (h) W. Wei, J. Yu, M. A. Gebbie, Y. Tan, N. R. Martinez Rodriguez, J. N. Israelachvili and J. H. Waite, Langmuir, 2015, 31, 1105; $(i)$ Q. Lin, D. Gourdon, C. Sun, N. Holten-Andersen, T. H. Anderson, J. H. Waite and J. N. Israelachvili, Proc. Natl. Acad. Sci. U. S. A., 2007, 104, 3782.

3 (a) H. J. Meredith, C. L. Jenkins and J. J. Wilker, Adv. Funct. Mater, , 2014, 24, 3259; (b) H. Shao, K. N. Bachus and R. J. Stewart, Macromol. Biosci., 2009, 9, 464; (c) H. Shao and R. J. Stewart, Adv. Mater., 2010, 22, 729.

4 M. Jia, A. Li, Y. Mu, W. Jiang and X. Wan, Polymer, 2014, 55, 1160.

5 Y. Liu and K. Li, Int. J. Adhes. Adhes., 2007, 27, 59.

6 G. Chen, C. Wang, J. Zhang, Y. Wang, R. Zhang, F. Du, N. Yan, Y. Kou and Z. Li, Macromolecules, 2010, 43, 9972.

7 J. H. Waite, Integr. Comp. Biol., 2002, 42, 1172.

8 B. P. Lee, J. L. Dalsin and P. B. Messersmith, Biomacromolecules, 2002, 3, 1038.

9 (a) K. S. Lee, Y. H. Park, A. K. Roy, B. Park, S. Y. Park and I. In, Chem. Lett., 2014, 43, 723; (b) T. Mosaiab, C. J. Jeong, G. J. Shin, K. H. Choi, S. K. Lee, I. Lee, I. In and S. Y. Park, Mater. Sci. Eng., C, 2013, 33, 3786. 